Bull. Chem. Soc. Ethiop. 2018, 32(2), 323-335.

ISSN 1011-3924

(c) 2018 Chemical Society of Ethiopia and The Authors

Printed in Ethiopia

DOI: https://dx.doi.org/10.4314/bcse.v32i2.11

\title{
INHIBITORY EFFECT OF ACACIA HAMULOSA METHANOLIC EXTRACT ON THE CORROSION OF MILD STEEL IN 1 M HYDROCHLORIC ACID
}

\author{
A. Bader ${ }^{1 *}$, U. Shaheen ${ }^{1,2}$, M.A.S. Aborehab ${ }^{3}$, Y. El Ouadi ${ }^{4}$, A. Bouyanzer ${ }^{4}$, B. Hammouti ${ }^{4 *}$ and \\ T. Ben Hadda ${ }^{5}$ \\ ${ }^{1}$ Department of Pharmacognosy, Faculty of Pharmacy, Umm Al-Qura University, Makkah- \\ 21955, Saudi Arabia \\ ${ }^{2}$ Department of Pharmacognosy, Faculty of Pharmacy, Al-Azhar University, Cairo, Egypt \\ ${ }^{3}$ Department of Pharmaceutics, Faculty of Pharmacy, Umm Al-Qura University, Makkah- \\ 21955, Saudi Arabia \\ ${ }^{4}$ Laboratoire de Chimie Appliquée et environnement (LCAE-URAC18), Faculté des Sciences, \\ Université Mohammed Premier, Oujda-60000, Morocco \\ ${ }^{5}$ Laboratoire Chimie Matériaux, FSO, Université Mohammed 1ER, Oujda-60000, Morocco
}

(Received February 26, 2015; Revised August 21, 2017; Accepted April 23, 2018)

\begin{abstract}
The flora of Saudi Arabia comprises about 18 species of Acacia species including Acacia hamulosa Benth. The methanolic extract of the flowering tops of $A$. hamulosa was tested for its radical scavenging activity toward 2,2-diphenyl-1-pricylhydrazyl (DPPH) radical and the activity was compared with L-ascorbic acid, quercetin and Trolox as standards. The total phenolic content was determined using Folin-Ciocalteu method. In addition the methanolic extract has been evaluated as a corrosion inhibitor for steel in $1 \mathrm{M} \mathrm{HCl}$ solution by means of weight loss measurements, potentiodynamic polarization, electrochemical impedance spectroscopy (EIS). Tafel polarization study revealed that extract of Acacia hamulosa acts as a cathodic type inhibitor. Inhibition was found to increase with increasing concentration of the extract of Acacia hamulosa. Values of inhibition efficiency calculated from weight loss, Tafel polarization curves, and EIS are in good agreement. The effect of temperature on the corrosion behaviour of mild steel in $1 \mathrm{M} \mathrm{HCl}$ with addition of extract was also studied and thermodynamic parameters were determined and discussed.
\end{abstract}

KEY WORDS: Acacia hamulosa, Extract, Polyphenols, Antioxidant corrosion, Electrochemical study

\section{INTRODUCTION}

Plants extracts and natural products became nowadays highly searched target for the discovery of safe and effective antioxidant and free radical scavenging activity agents $[1,2]$. Synthetic antioxidant, such as butylhydroxytoluene (BHT) and butylhydroxyanisole (BHA) can be carcinogenic $[3,4]$. For this reason, scientists propose to replace them with natural antioxidant due to their beneficial effects and low toxicity. Beside the antioxidant and free radical scavenging activity, plants extracts became also a target for the discovery of natural inhibitors of steel corrosion. Iron has played a central role in human society due to its excellent mechanical properties and the abundance of its ores. Today, iron is used in much larger quantities than any other metallic material and is indispensable in infrastructure, transportation, and manufacturing. The steel is widely used in many applications such as desalination plants, construction materials, pharmaceutical industry, and thermal power plant, due to their stability, good corrosion resistance, high strength, workability and weld ability $[5,6]$.

Corrosion is the deterioration of essential properties of a material due to reactions with its surroundings. Much of this loss is due to the corrosion of iron and steel, although many other metals may corrode as well. Corrosion damage can cause leakage of fluids or gases. Even more

*Corresponding author. E-mail: hammoutib@gmail.com, ammarosio@yahoo.it

This work is licensed under the Creative Commons Attribution 4.0 International License 
dangerous is a loss of strength of the structure induced by corrosion and subsequent failure. Acid solutions are widely used in industry: some of the important fields of application are acid pickling of steel, chemical cleaning and processing, ore production and oil well acidizing. As ordinary acids, $\mathrm{HCl}$ and $\mathrm{H}_{2} \mathrm{SO}_{4}$ are usually used as industrial acids, cleaning and pickling acids. A major drawback is the susceptibility of iron to corrosion [7-9].

For several years, the interest of our team, is the valorization of natural products from aromatic and medicinal plants, using them as natural antioxidants [10-12] and ecofriendly corrosion inhibitors [13-22].

In this study, the methanolic extract of the aerial part of Acacia hamulosa Benth was used for the antioxidant and anticorrosive activity. This plant was harvested from Saudi Arabia. Previous works on plant belonging on the same genus: Acacia raddiana, Acacia senegal (Gum Arabic) and Acacia cyanophylla were performed [23-25]. The aim of this work was to study the antioxidant effect, total phenols content and anti-corrosion properties by gravimetric method and electrochemical techniques such as potentiodynamic polarization and electrochemical impedance spectroscopy (EIS).

\section{EXPERIMENTAL}

\section{Preparing of Acacia hamulosa methanol extract}

Plant material. The flowering aerial tops were collected in Al-Kurr, (Makkah) Saudi Arabia in September 2013 and identified by Ammar Bader. A voucher specimen sample No. SA$\mathrm{Ma} / 2013 / 1$ was deposited at the herbarium of Pharmacognosy lab at the Faculty of Pharmacy in Umm Al-Qura University, Saudi Arabia. The plant material was air dried in shadow. $50 \mathrm{~g}$ of finely grinded plant material were extracted by maceration in $200 \mathrm{~mL}$ of methanol, the soaked plant material was left under sonication for $10 \mathrm{~min}$. The filtered extract was evaporated yielding $7.85 \mathrm{~g}$.

\section{Analysis of total phenols}

The total polyphenol content of the crude plant extracts were measured using Folin-Ciocalteu reagent method [26] with slight modification. A $0.1 \mathrm{~mL}$ of diluted extracts was transferred into test tubes and their volumes were made up to $0.5 \mathrm{~mL}$ with distilled water. After addition of 0.25 $\mathrm{mL}$ Folin-Ciocalteu reagent (Sigma-Aldrich) $(0.2 \mathrm{~N})$ and $1.25 \mathrm{~mL}$ of $20 \%$ aqueous sodium carbonate solution, tubes were vortexed for $1 \mathrm{~min}$ and the absorbance of the blue colored solution was measured at $765 \mathrm{~nm}$ after $40 \mathrm{~min}$ of incubation at room temperature in dark against blank containing $0.1 \mathrm{~mL}$ of the extracting solvent instead of the tested samples using Jenway $8000 \mathrm{UV} / \mathrm{V}$ is spectrophotometer. All samples and readings were prepared and measured in triplicate. Gallic acid was used as standard. $0.5 \mathrm{mg} / \mathrm{mL}$ stock standard solution of gallic acid was prepared by dissolving $250 \mathrm{mg}$ of dry gallic acid in $1 \mathrm{~mL}$ of extracting solvent and then diluted to $500 \mathrm{~mL}$ of distilled water. The stock solution was stored at $277 \mathrm{~K}$. Working standards of between 0.01 and $0.10 \mathrm{mg} / \mathrm{mL}$ were prepared by diluting the stock solution with distilled water. The standard calibration curve of gallic acid $(0.01-0.10 \mathrm{mg} / \mathrm{mL})$ was constructed by plotting the absorbance against the concentration (Figure 1).

\section{Radical scavenging activity on DPPH radical}

Free radical scavenging activity of $A$. hamulosa methanolic extract was determined using the DPPH method. An aliquot $(0.5 \mathrm{~mL})$ of methanolic solution containing test drug at various concentrations $(10 \mu \mathrm{g}$ to $500 \mu \mathrm{g} / \mathrm{mL})$ was added to equal volume of freshly prepared methanolic DPPH $(100 \mu \mathrm{M})$ solution; after incubation for $20 \mathrm{~min}$ at room temperature, absorbance was measured at $517 \mathrm{~nm}$ by a spectrophotometer [27]. The antioxidant assay was carried out in 
triplicate and the readings were averaged. The scavenging activity was measured as the decrease in absorbance of the samples vs. DPPH standard solution.

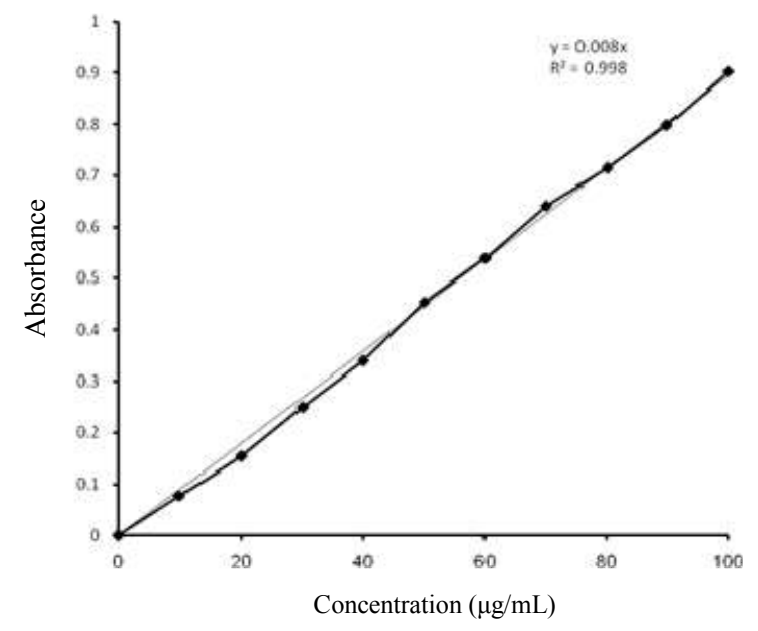

Figure 1. Standard calibration curve of gallic acid.

Gravimetric study

The gravimetric method (weight loss, $\mathrm{W}_{\mathrm{L}}$ ) is known to be the most widely used method of monitoring inhibition efficiency [28]. The mild steel specimens of dimension $1 \mathrm{x} 1 \mathrm{x} 0.1 \mathrm{~cm}$ were used in these studies. The weight loss measurements were conducted under total immersion using $250 \mathrm{~mL}$ capacity beakers containing $100 \mathrm{~mL}$ of test solutions, $1 \mathrm{M} \mathrm{HCl}$ solution containing the inhibitor (extract of Acacia hamulosa) at different concentrations, for 6 hours at different temperature, maintained in a thermostated water bath. Immersion is subjected to a temperature of $308 \mathrm{~K}$ to 6 hours. The specimens were weighed before and after the tests using an analytical balance with a precision of $0.1 \mathrm{mg}$. The specimens were taken out after the 6 hours of immersion, washed, dried and reweighed accurately to determine the weight loss of mild steel.

All measurements were performed few times and average values were reported to obtain good reproducibility. The corrosion rate $(\rho)$ in $\mathrm{mg} \mathrm{cm}^{-2} \mathrm{~h}^{-1}$ in the absence and presence of extract was determined using the following equation:

$\rho=\frac{\Delta W}{\text { At }}$

where $\Delta \mathrm{W}$ is the average weight loss of the mild steel specimens, $\mathrm{A}$ is the total area of mild steel specimen and $t$ is the immersion time. The percentage inhibition efficiency (IE\%) was calculated using the relationship:

$\operatorname{IE}(\%)=\frac{W 0-W i}{W 0} \times 100$

where $\mathrm{W}_{\mathrm{o}}$ and $\mathrm{W}_{\mathrm{i}}$ are the weight loss values in the absence and presence of extract. Temperature corrosive environment is a factor that can affect the efficacy of inhibiting it. Given the importance of this factor, we performed tests of mass loss of steel in $1 \mathrm{M} \mathrm{HCl}$ with and without 
addition of the inhibitor (extract of Acacia hamulosa) at different temperatures between 313 and $343 \mathrm{~K}$.

\section{Electrochemical measurements}

The EIS is a method designed to avoid severe deterioration of the exposed surface of the structure studied and was widely used for monitoring the corrosion of a working electrode. This method consists of applying frequencies and low amplitude sinusoidal voltage wave to produce perturbation signals on the working electrode. The corrosion state can be predicted by analyzing the current response of the voltage or the frequencies. In modern practice, the impedance is usually measured with lock-in amplifiers or frequency-response analyzers, which are faster and more convenient than impedance bridges [29].

The electrolysis cell was Pyrex cylinder closed by cap containing five openings. Three of them were used for the electrodes. The working electrode was mild steel with the surface area of $1 \mathrm{~cm}^{2}$. Before each experiment, the electrode was polished using emery paper until 1200 grade. After this, the electrode was cleaned ultrasonically with distillate water. A saturated calomel electrode (SCE) was used as a reference. All potentials were given with reference to this electrode. The counter electrode was a platinum plate of surface area of $1 \mathrm{~cm}^{2}$. The temperature was thermostatically controlled at $308 \pm 1 \mathrm{~K}$. The working electrode was immersed in test solution during 30 min until a steady state open circuit potential $\left(\mathrm{E}_{\mathrm{ocp}}\right)$ was obtained. The polarization curve was recorded by polarization from $-800 \mathrm{mV}$ to $100 \mathrm{mV}$ under potentiodynamic conditions corresponding to $0.5 \mathrm{mV} / \mathrm{s}$ (sweep rate) and under air atmosphere.

The potentiodynamic measurements were carried out using VoltaLab100 electrochemical analyser, which was controlled by a personal computer. AC-impedance studies also were carried out in a three electrode cell assembly. The data were analysed using Voltamaster 4.0 software. The electrochemical impedance spectra (EIS) were acquired in the frequency range $10 \mathrm{kHz}$ to 1 $\mathrm{mHz}$ at the free corrosion potential. The charge transfer resistance $\left(\mathrm{R}_{\mathrm{ct}}\right)$ and double layer capacitance $\left(\mathrm{C}_{\mathrm{dl}}\right)$ were determined from Nyquist plots. The impedance diagrams are given in the Nyquist representation. Experiments are repeated three times to ensure the reproducibility.

\section{RESULTS AND DISCUSSION}

\section{Total phenols content}

Quantitative analyses extract of Acacia hamulosa methanolic extract was done using FolinCiocalteu method to determine the total phenols expressed as gallic acid equivalent and it was $77.97 \pm 4.93$ of GAE $/ 100 \mathrm{~g} \pm \mathrm{SD}$. This value indicates clearly that the methanolic extract of the aerial part of Acacia hamulosa is rich in polyphenol.

The values of free radical scavenging activity on DPPH by the methanolic extract of Acacia hamulosa is reported in Table 1 in comparison with antioxidant standards. The antioxidant activity of the methanolic extract of Acacia hamulosa is very interesting $(89.05$ to $100 \mu \mathrm{g} / \mathrm{mL})$. This value is due to the high amount of polyphenols present in the extract. Despite the high antioxidant activity of the methanolic extract $(89.05 \%)$, this value is still lower than that found by Trolox, L-ascorbic acid and quercetin. The antioxidant activity of the samples studied varies as follows:

$$
\text { Methanolic extract }<\text { Quercetin }<\text { Trolox }<\text { L-ascorbic acid. }
$$

Table 1.\% of free radical scavenging activity on DPPH by the methanolic extract of $A$. hamulosa and antioxidant standards. 


\begin{tabular}{|c|c|c|c|c|}
\hline Concentration $(\mu \mathrm{g} / \mathrm{mL})$ & A. hamulosa & Trolox & L-ascorbic acid & Quercetin \\
\hline 0 & 0 & 0 & 0 & 0 \\
\hline 10 & 36.38 & 91.22 & 90.07 & 89.12 \\
\hline 20 & 72.49 & 92.31 & 92.09 & 89.91 \\
\hline 40 & 87 & 92.82 & 92.85 & 90.17 \\
\hline 50 & 88.25 & 93.06 & 93.09 & 90.3 \\
\hline 80 & 88.37 & 93.15 & 93.19 & 90.49 \\
\hline 100 & 89.05 & 93.24 & 93.26 & 90.62 \\
\hline
\end{tabular}

\section{Electrochemical impedance measurements}

Among the different electrochemical techniques that can be used to study corrosion inhibitors, EIS appears as powerful tool for the information that can provide, as for example, double layer capacitance $\left(\mathrm{C}_{\mathrm{dl}}\right)$, and polarization resistance values $\left(\mathrm{R}_{\mathrm{p}}\right)$. Changes in these parameters as a function of time or with respect to other variables, allow obtaining important information about the kinetics of the corrosion process being involved [30].

In some cases impedance data obtained at the corrosion potential, $\mathrm{E}_{\text {corr }}$ have the shape of depressed semicircles with the centre of the semicircle below the real axis. The corrosion behaviour of mild steel in $1 \mathrm{M} \mathrm{HCl}$ solution, in the absence and presence of extract of Acacia hamulosa, was investigated by the EIS at $308 \mathrm{~K}$ after 1 hour of immersion. The charge-transfer resistance values were obtained from the diameter of the semicircles of the Nyquist diagrams. The inhibition efficiency ( $\mathrm{E} \%$ ) of the inhibitor has been found out from the charge transfer resistance values using the following equation:

$\mathrm{E}(\%)=\frac{\mathrm{R}^{\circ} \text { corr }- \text { Rcorr }}{\mathrm{R}^{\circ} \mathrm{Corr}} \times 100$

where, $\mathrm{R}_{\text {corr }}^{\mathrm{o}}$ and $\mathrm{R}_{\text {corr }}$ are the charge transfer resistance in presence and in absence of inhibitor, respectively. All electrochemical measurements were done in unstirred and non deaerated solutions. The electrochemical impedance plots for mild steel in $1 \mathrm{M} \mathrm{HCl}$ solution in the absence and presence of various concentrations of Extract of Acacia hamulosa are shown in Nyquist, Bode modulus as well as phase angle representations (Figure 2). Table 2 summarizes impedance data from the EIS experiments carried out in the absence and presence of increasing the extract concentrations.

The electrochemical impedance curves indicate two significant effects in absence and presence of extract of Acacia hamulosa: the charge transfer resistance significantly increases, and the $f_{\max }$ varies, in the presence of the inhibitors studied, decreasing the capacitance value, which may be caused by reduction in the local dielectric constant and/or by an increase in the thickness of the electrical double-layer. Bode representation suggests a onetime constant Bode plot. The phase angle at higher frequencies is attributed anticorrosion performance. The more negative values of phase angle at high frequencies, indicating that there was greater surface coverage and transfer charge resistance [31]. These results show that the presence of the inhibitors modifies the electric double-layer structure suggesting that the inhibitor molecules act by adsorption at the metal/solution interface. Furthermore, $\mathrm{C}_{\mathrm{dl}}$ decreases with increase of the concentration of inhibitors. This phenomenon is generally related to the adsorption of organic molecules on the metal surface and then leads to a decrease in the dielectric constant and/or an increase in the thickness of the electrical double layer [32].

$C_{d l}=\frac{\varepsilon 0 \varepsilon}{\delta} \mathrm{S}$

where $\delta$ is the thickness of the protective layer, $\mathrm{S}$ is the electrode area, $\varepsilon_{O}$ the vacuum permittivity and $\varepsilon$ is dielectric constant of the medium. 

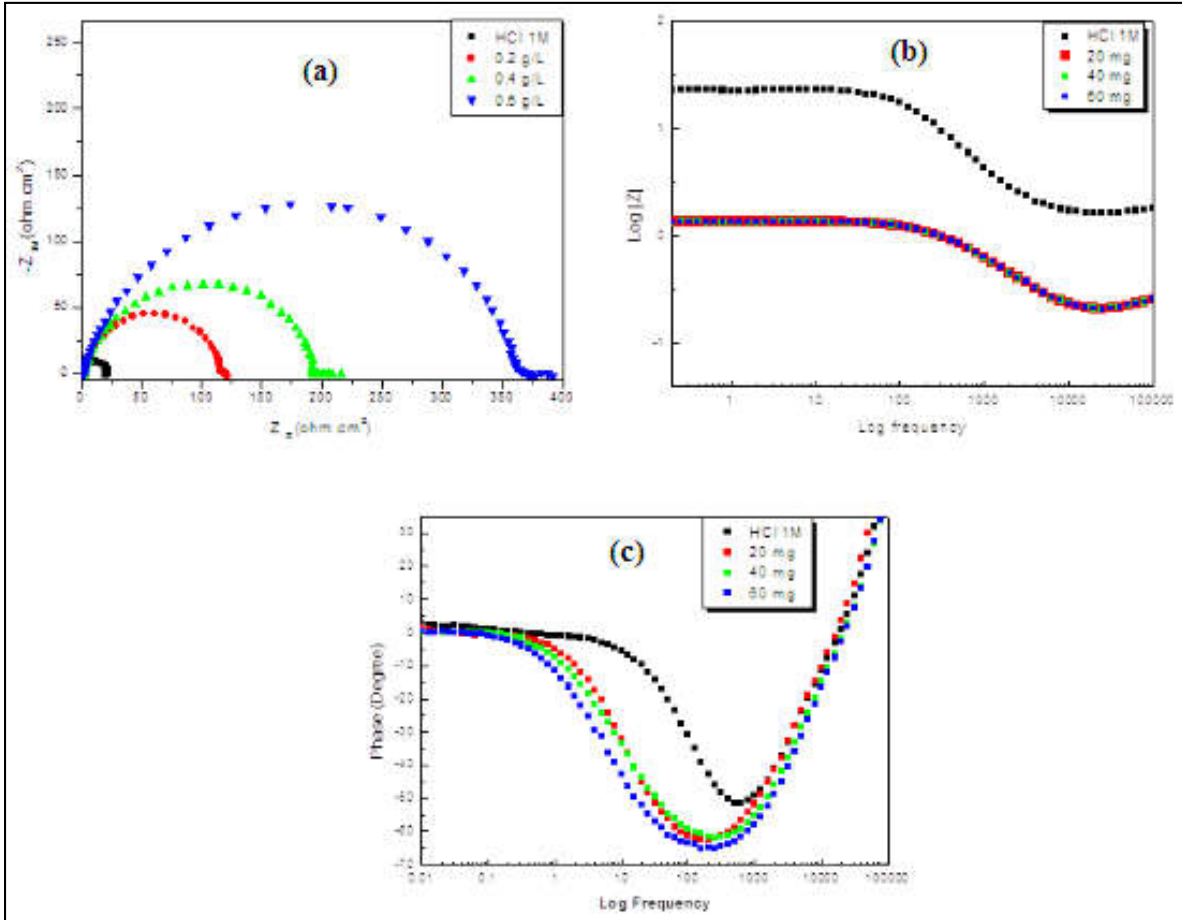

Figure 2. EIS plots in absence and presence of different concentrations of extract of Acacia hamulosa in $\mathrm{HCl} 1 \mathrm{M}$ : a) Nyquist, b) Bode modulus and c) phase angle representations.

Table 2. Corrosion parameters obtained by impedance measurements for mild steel in $\mathrm{HCl} 1 \mathrm{M}$ at various concentrations of extract of Acacia hamulosa.

\begin{tabular}{|c|c|c|c|c|}
\hline Inhibitor concentration & $\mathrm{R}_{\mathrm{ct}}\left(\mathrm{ohm}_{\mathrm{cm}}{ }^{2}\right)$ & $\mathrm{f}_{\max }(\mathrm{Hz})$ & $\mathrm{C}_{\mathrm{dl}}\left(\mu \mathrm{F} / \mathrm{cm}^{2}\right)$ & $\mathrm{E}(\%)$ \\
\hline $\mathrm{HCl} 1 \mathrm{M}$ & 21.68 & 125 & 58.73 & -- \\
\hline $0.2 \mathrm{~g} / \mathrm{L}$ & 116.5 & 125 & 10.93 & 81.39 \\
\hline $0.4 \mathrm{~g} / \mathrm{L}$ & 195.6 & 100 & 8.14 & 88.92 \\
\hline $0.6 \mathrm{~g} / \mathrm{L}$ & 363.9 & 63.29 & 6.91 & 94.04 \\
\hline
\end{tabular}

For other part, a low capacitance may result if water molecules at the electrode interface are largely replaced by organic inhibitor molecules through adsorption. The larger inhibitor molecules also reduce the capacitance through the increase in the double layer thickness [33]. Deviations from a perfect circular shape indicate frequency dispersion of interfacial impedance. This anomalous phenomenon is attributed in the literature to the non-homogeneity of the electrode surface arising from the surface roughness or interfacial phenomena [34]. The charge transfer resistance $\left(\mathrm{R}_{\mathrm{ct}}\right)$ values were calculated from the difference in impedances at lower and higher frequencies. The double layer capacitance $\left(\mathrm{C}_{\mathrm{dl}}\right)$ was calculated from equation 5 :

$$
C_{d l}=\frac{1}{2 \pi f_{\max } R_{c t}}
$$

where $f_{\max }$ is the maximum frequency at which the imaginary component of the impedance is maximal. 
The EIS results of these capacitive loops are simulated by the equivalent circuit shown in Figure 3 to pure electric models that could verify or rule out mechanistic models and enable the calculation of numerical values corresponding to the physical and/or chemical properties of the electrochemical system under investigation. In the electrical equivalent circuit, $R_{s}$ is the electrolyte resistance, $R_{c t}$ the charge transfer resistance and $C_{d l}$ is the double layer capacitance.

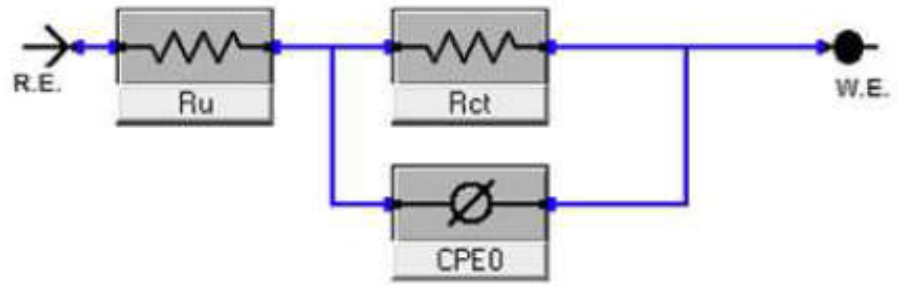

Figure 3. Electrical equivalent circuit model used for the modeling metal/solution.

From Table 2, it is clear that the $\mathrm{R}_{\mathrm{ct}}$ values increased and that the $\mathrm{C}_{\mathrm{dl}}$ values decreased with increasing inhibitor concentration. These results indicate a decrease in the active surface area caused by the adsorption of the inhibitors on the mild steel surface, and it suggests that the corrosion process became hindered. The best result for the inhibition efficiency of extract of Acacia hamulosa was obtained at a concentration of $0.6 \mathrm{~g} / \mathrm{L}$, with efficiency equal to $94.04 \%$.

\section{Tafel polarization curves}

The type of experiment was performed as described in recent research [21-22, 32] at $308 \mathrm{~K}$. Immediately upon immersion of the samples in the electrolytes, the open circuit potential (OCP) was monitored for one hours. This was followed by potentiodynamic anodic polarisation measurements. Lastly, in order to investigate whether corrosion products formed on the sample surfaces, the anodic polarisation tests were carried out on the same surface and in the same test solution. All tests were done at room temperature using electrolytes that were not de-aerated during testing. Polarization curves for mild steel in presence and absence of different concentrations of extract of Acacia hamulosa in non-aerated solutions are shown in Figure 4. The extrapolation of Tafel straight line allowed the calculation of the corrosion current density $\left(\mathrm{I}_{\text {corr }}\right)$. The values of $\mathrm{I}_{\text {corr }}$, the corrosion potential $\left(\mathrm{E}_{\text {corr }}\right)$, cathodic Tafel slope $\left(\beta_{\mathrm{c}}\right)$, and inhibition efficiency $(\mathrm{E} \%)$ are given in Table 2 for the Extract. The (E \%) was calculated using the following equation $[35,36]$.

$$
E(\%)=\frac{I^{\circ} \operatorname{corr}-I \operatorname{corr}}{I^{\circ} \operatorname{corr}} x 100
$$

where $\mathrm{I}^{\mathrm{o}}$ corr and $\mathrm{I}_{\text {corr }}$ are uninhibited and inhibited corrosion current densities, respectively. Under the experimental conditions performed, the cathodic branch represents the hydrogen evolution reaction, while the anodic branch represents the iron dissolution reaction.

From Figure 4, it is clear that the polarization curves in $1.0 \mathrm{M} \mathrm{HCl}$ solutions with different concentrations of Acacia hamulosa extract, are almost similar: both anodic and cathodic reactions of mild steel electrode corrosion were inhibited, which suggested that this inhibitor reduce anodic dissolution and also retard the hydrogen evolution reaction. Cathodic Tafel curves give rise to parallel Tafel lines, indicating that the hydrogen evolution reaction is activationcontrolled and the addition of the inhibitors does not affect the reduction mechanism, and their inhibition action is simply blocking the metal surface. 
Table 3 reveals that in presence of inhibitor, the value of corrosion density $\left(\mathrm{I}_{\text {corr }}\right)$ was decreased. This behaviour reflects its ability to inhibit the corrosion of mild steel in $1 \mathrm{M} \mathrm{HCl}$ solution. The E (\%) increases as the extract concentration is increased. It is also worth noting that the value of $\beta \mathrm{c}$ changes with the addition of Acacia hamulosa extract more than the value of $\beta a$. This indicates that the Acacia hamulosa extract behave cathodically more than anodically.

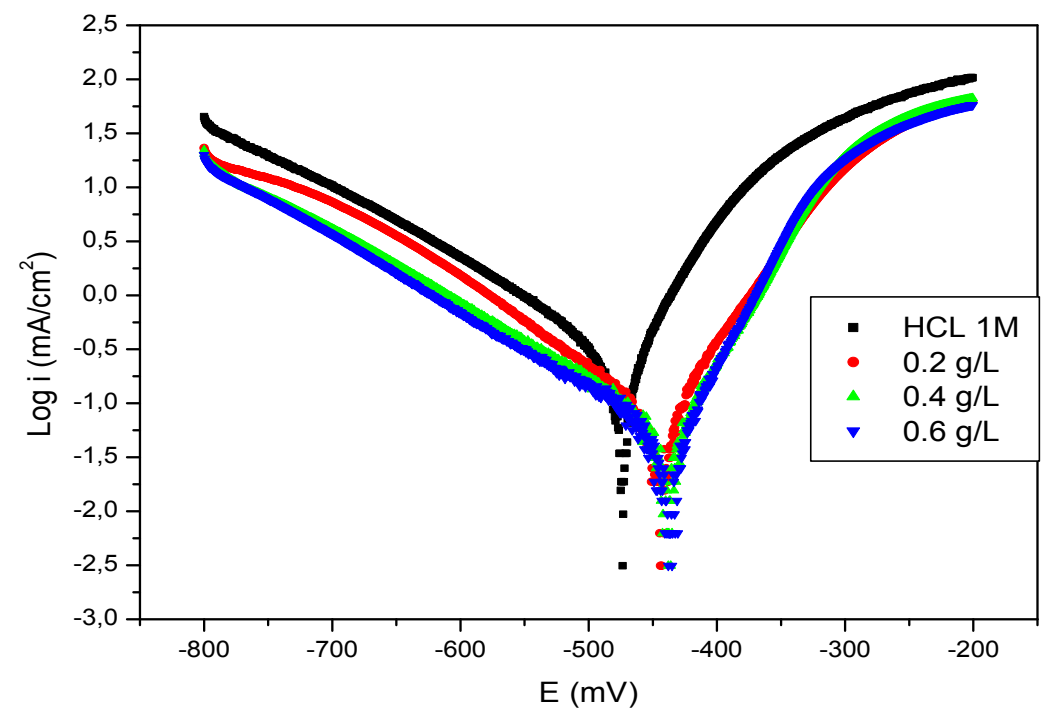

Figure 4. Tafel polarization curves in in $\mathrm{HCl} 1 \mathrm{M}$ with and without extract of Acacia hamulosa at different concentrations.

Table 3. Tafel polarization curves in $1 \mathrm{M} \mathrm{HCl}$ with and without extract of Acacia hamulosa in $\mathrm{HCl} 1 \mathrm{M}$.

\begin{tabular}{|c|c|c|c|c|c|}
\hline Inhibitor concentration & $-\mathrm{E}_{\text {Corr }}(\mathrm{mV})$ & $\beta_{\mathrm{C}}(\mathrm{mV} / \mathrm{dec})$ & $\beta_{\mathrm{a}}(\mathrm{mV} / \mathrm{dec})$ & $\mathrm{I}_{\mathrm{Corr}}\left(\mathrm{mA} / \mathrm{cm}^{2}\right)$ & $\mathrm{E}(\%)$ \\
\hline $\mathrm{HCl} 1 \mathrm{M}$ & 474.1 & -152 & 63.8 & 0.3416 & -- \\
\hline $0.2 \mathrm{~g} / \mathrm{L}$ & 444.5 & -122.9 & 61.5 & 0.0822 & 75.94 \\
\hline $0.4 \mathrm{~g} / \mathrm{L}$ & 438.9 & -138.8 & 52.7 & 0.0581 & 82.99 \\
\hline $0.6 \mathrm{~g} / \mathrm{L}$ & 436.9 & -118.6 & 42.2 & 0.026 & 92.39 \\
\hline
\end{tabular}

\section{Effect of temperature}

Temperature has a great effect on the corrosion phenomenon. Generally the corrosion rate increases with the rise of the temperature. For this purpose, we made weight loss experiments in the range of temperature 313-343 K, in the absence and presence of various concentrations of Acacia hamulosa extract after $1 \mathrm{~h}$ of immersion at optimum concentration $(0.6 \mathrm{~g} / \mathrm{L})$. The corresponding data are shown in Figure 5, which clearly shows that the extract retards the corrosion rate of the mild steel in the test solutions. From the weight loss results, the corrosion rate $\left(C_{R}\right)$, the inhibition efficiency $(E \%)$ of inhibitors and degree of surface coverage $(\Theta)$ were calculated using equations 7-9 [37].

$$
C R=\left(\frac{\Delta W}{S x t}\right)
$$




$$
\begin{aligned}
& E(\%)=\left(1-\frac{W_{\text {corr }}}{W_{\text {corr }}^{o}}\right) x 100 \\
& \theta=\left(1-\frac{W_{\text {corr }}}{W_{\text {corr }}^{o}}\right)
\end{aligned}
$$

where $\mathrm{W}_{\text {corr }}$ and $\mathrm{W}^{\circ}$ corr are the weight losses for mild steel in the presence and absence of the inhibitor in $\mathrm{HCl}$ solution and $\Theta$ is the degree of surface coverage of the inhibitors. $\Delta \mathrm{W}$ is the difference of weight loss for mild steel with and without inhibitors, $\mathrm{S}$ is the exposure area of the metallic specimens and $t$ is the immersion time of the metal in corrosive solution.

The fractional surface coverage $(\Theta)$ can be easily determined from the weight loss measurements by the ratio $\mathrm{E}(\%) / 100$, where $\mathrm{E}(\%)$ is inhibition efficiency and calculated using equation 8. The data obtained suggest that Acacia hamulosa extract get adsorbed on the steel surface at all temperatures studied and corrosion rates increased in absence and presence of inhibitor with increase in temperature in $1 \mathrm{M} \mathrm{HCl}$ solutions. In acidic media, corrosion of metal is generally accompanied with evolution of $\mathrm{H}_{2}$ gas; rise in temperature usually accelerates the corrosion reactions which results in higher dissolution rate of the metal.

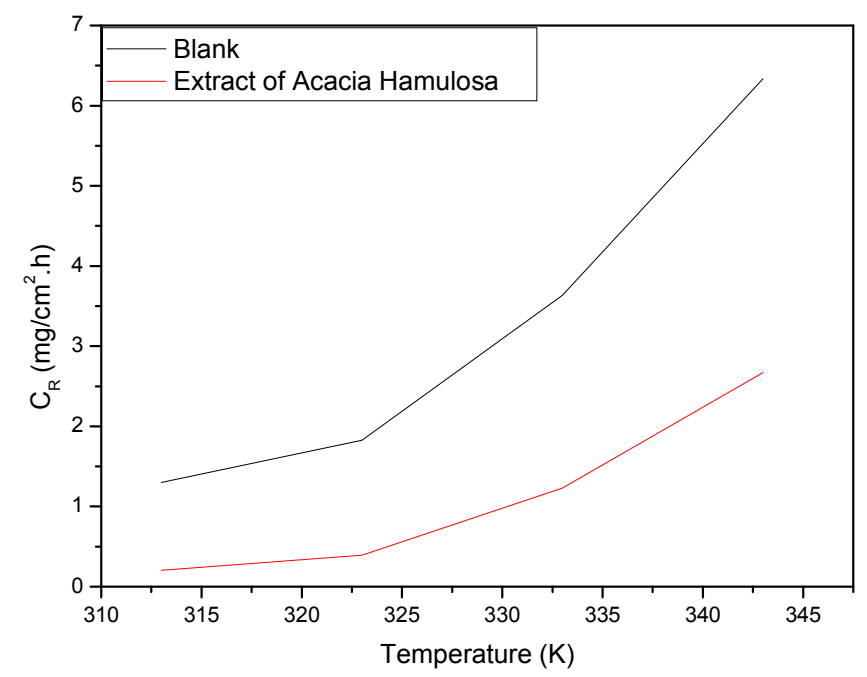

Figure 5. Variation of $\mathrm{CR}$ in $1 \mathrm{M} \mathrm{HCl}$ on steel surface without and with of optimum concentration of extract Acacia hamulosa at different temperatures.

From Figure 5, it is clear that corrosion rate increased with increasing temperature both in uninhibited and inhibited solutions while the inhibition efficiency of Acacia hamulosa extract decreased with temperature. A decrease in inhibition efficiencies with the increase temperature in presence of Acacia hamulosa extract might be due to weakening of physical adsorption.

\section{Scanning electron microscopy analysis}

The study of surface morphology of corroded and non-corroded metals is very important. For this purpose, scanning electron microscopy (SEM) is used to analyze the surface of metals. 
The images of scanning electron microscopy confirmed the interaction of the inhibitor studied and the surface of mild steel. The recording of the scanning electron microscopy images was carried out for the mild steel samples before and after immersion in an acid medium, in the presence and absence of Acacia hamulosa extract. The images are grouped in Figure 6. Figure 6a shows the SEM image of a sample of freshly abraded mild steel without treatment. The same figure indicates that the surface of the mild steel is smooth, except that there are some minor scratches, which could have arisen during the abrasion. Figure $6 \mathrm{~b}$ shows the image of the soft steel sample immersed in $1.0 \mathrm{M} \mathrm{HCl}$ for $6 \mathrm{~h}$. It is noted that the surface of the mild steel was rigorously corroded because of the aggressive attack of $1.0 \mathrm{M} \mathrm{HCl}$. Figure $6 \mathrm{c}$ shows the SEM image of the mild steel immersed in the acid solution in the presence of the optimum concentration of Acacia hamulosa extract $\left(10^{-3} \mathrm{M}\right)$ for 6 hours. It is clear that the surface of the mild steel is particularly smooth in comparison with that taken in Figure 6a. From the comparison between Figures $6 \mathrm{a}, \mathrm{b}, \mathrm{c}$, and the results obtained above, it is clear that a protective film has been formed by the inhibitory molecules on the surface of the mild steel, which leads to a significant inhibition of the corrosion of mild steel in $1 \mathrm{M} \mathrm{HCl}$.

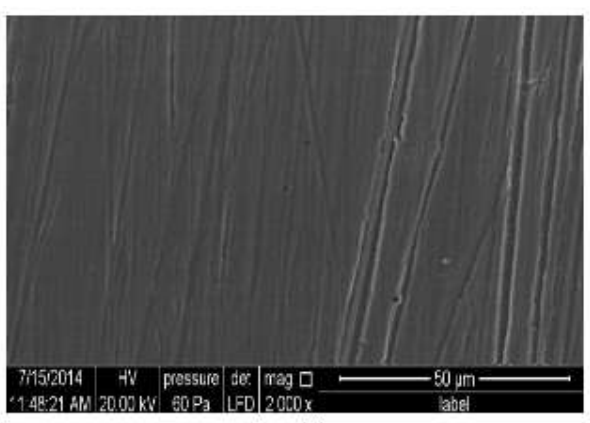

(a)

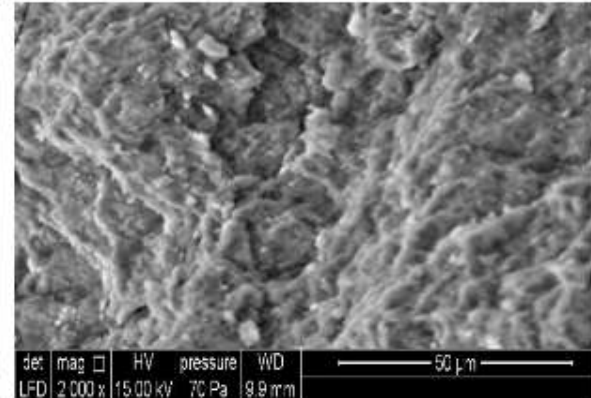

(b)

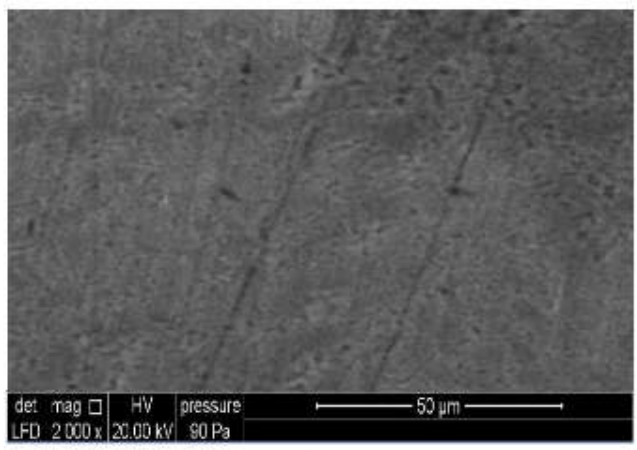

(c)

Figure 6. SEM images of steel samples (a): before immersion, (b): after immersion for $6 \mathrm{~h}$ in $\mathrm{HCl}$ medium at absence of inhibitor and; (c): after immersion for $6 \mathrm{~h}$ in $\mathrm{HCl}$ medium at optimum concentration of the inhibitor.

\section{CONCLUSIONS}

The purpose of this paper is divided into three parts: (i) determination of the amount of polyphenols present in the methanolic extract of Acacia hamulosa, (ii) the antioxidant activity 
using the DPPH method, and (iii) the anticorrosive activity by the electrochemical methods. According to the results obtained, we can conclude that the methanolic extract is rich in polyphenols. Acacia hamulosa extract, has significant antioxidant activity. This gives the impression that the extract studied can replace the synthetic antioxidants which presents harmful impacts on the environment and the human being. Tafel polarization measurements indicates that Acacia hamulosa extract act behave cathodically more than anodically. The increase in the charge transfer resistance and decrease in double layer capacitance values, with the increase in the inhibitor concentration, showed that Acacia hamulosa extract formed protective layers on the mild steel surface, covering areas where $\mathrm{HCl}$ solution degrades and corrodes rapidly. It's clear that the inhibition efficiency increases with increase in the concentration of Acacia hamulosa extract but decreases with rise in temperature. We can add that the corrosion process was inhibited by adsorption of the organic matter on the mild steel surface, obtaining the formation of the film on the metal/acid solution interface, decreasing the degradation of the material. Finally, the results obtained through weight loss measurements and electrochemical tests demonstrated that extract of Acacia hamulosa act as efficient corrosion inhibitors of the mild steel in $1 \mathrm{M} \mathrm{HCl}$ solution.

\section{ACKNOWLEDGEMENTS}

This study was financially supported by Institute of Scientific Research and Revival of Islamic Heritage at Umm Al-Qura University, Makkah, Saudi Arabia (Project ID: 4331012). The authors are thankful to the Director of Laboratory of Applied Analytical Chemistry, Materials and Environment, who facilitated the access of PhD Hajar Bendaiffor collaboration.

\section{REFERENCES}

1. Milella, L.; Bader, A.; De Tommasi, N.; Russo, D.; Braca, A. Antioxidant and free radicalscavenging activity of constituents from two Scorzonera species. Food Chem. 2014, 160, 298-304.

2. Siciliano, T.; Bader, A.; Vassallo, A.; Braca, A.; Morelli, I.; Pizza, C.; De Tommasi, N. Secondary metabolites from Ballotaundulata (Lamiaceae). Biochem. Syst. Ecol. 2005, 33, 341-351.

3. Ito, N.; Fukushima, S.; Hagiwara, A.; Shibata, M.; Ogiso, T. Carcinogenicity of butylatedhydroxyanisole in F344 rats. J. Natl. Cancer Inst. 1983, 70, 343-352.

4. Branen, A.L. Toxicology and biochemistry of butylated hydroxyanisole and butylated hydroxytoluene. J. Am. Oil Chem. Soc. 1975, 52, 59-63.

5. Chen, X.Z.; Shen, Z.; Li, P.; Bruce, M.; Huang, Y.M.; Lei, Y.C.; Huang, Q.Y.; Zhou, G.Z. Compatibility of CLAM steel weldments with static LiPb alloy at $550{ }^{\circ} \mathrm{C}$. Fusion Eng. Des. 2012, 87, 1565-1569.

6. Chetouani, A.; Daoudi, M.; Hammouti, B.; Ben Hadda, T.; Benkaddour, M. Inhibition of pure iron by new synthesized tripyrazole derivatives in $\mathrm{HCl}$ solution. Corros. Sci. 2006, 48, 2987-2997.

7. El Ayyoubi, S.; Chetouani, A.; Hammouti, B.; Warthan, A.; Mansri, A., Al-Deyab, S.S. Corrosion inhibition of iron in $1 \mathrm{M} \mathrm{HCl}$ by three quaternized copolymers poly(4vinylpyridine-g-polyethylene-oxide. Int. J. Electrochem. Sci. 2012, 7, 1639-1655.

8. Smallman, R.E.; Ngan, A.H.W. Chapter 14 - Selected Alloys, Modern Physical Metallurgy, 8th ed., Oxford: Butterworth-Heinemann; 2014; p 529.

9. Sazou, D.; Kominia, A.; Pagitsas, M. Corrosion processes of iron in acidic solutions associated with potential oscillations induced by chlorates and perchlorates. J. Solid State Electrochem. 2014, 18, 347-360. 
10. El Ouadi, Y.; Amirou, A.; Bouyanzer, A.; Elmsellem, H.; Majidi, L.; Bouhtit, F.; Hammouti, B. Antioxidant activity of phenols and flavonoids contents of aqueous extract of Salvia Officinalis origin in the North-East Morocco. Maghr. J. Pure Appl. Sci. 2015, 1, 18-24.

11. Naceiri Mrabti, H.; Marmouzi, I.; Sayah, K.; Chemlal, L.; El Ouadi, Y.; Elmsellem, H.; Cherrah, Y.; My Faouzi, A. Arbutus unedo L. aqueous extract is associated with in vitro and in vivo antioxidant activity. J. Mater. Environ. Sci. 2017, 8, 217-224.

12. El Ouadi, Y.; Bendaif, H.; Mrabti, H.N.; Elmsellem, H.; Kadmi, Y.; Shariati, M.A.; AbdelRahman, I.; Hammouti, B.; Bouyanzer, A. Antioxidant activity of phenols and flavonoids contents of aqueous extract of Pelargonium graveolens origin in the north-east Morocco. $J$ Microbiol. Biotechnol. Food Sci. 2017, 6, 1218-1220.

13. El Ouadi, Y.; Bouyanzer, A.; Majidi, L.; Paolini, J.; Desjobert, J.M.; Costa, J.; Chetouani, A.; Hammouti, B. Salvia officinalis essential oil and the extract as green corrosion inhibitor of mild steel in hydrochloric acid. J. Chem. Pharm. Res. 2014, 6, 1401-1416.

14. El Ouadi, Y.; Bouyanzer, A.; Majidi, L.; Paolini, J.; Desjobert, J.-M.; Costa, J.; Chetouani, A.; Hammouti, B.; Jodeh, S.; Warad, I.; Mabkhot, Y.; Ben Hadda, T. Evaluation of Pelargonium extract and oil as eco-friendly corrosion inhibitor for steel in acidic chloride solutions and pharmacological properties. Res. Chem. Intermed. 2015, 41, 7125-7149.

15. EL Ouadi, Y.; Bouratoua, A.; Bouyanzer, A.; Kabouche, Z.; Touzani, R.; EL Msellem, H.; Hammouti, B.; Chetouani, A. Effect of Athamanta sicula oil on inhibition of mild steel corrosion in $1 \mathrm{M} \mathrm{HCl}$. Der Pharma Chem. 2015, 7, 103-111.

16. Manssouri, M.; El Ouadi, Y.; Znini, M.; Costa, J.; Bouyanzer, A.; Desjobert, J-M.; Majidi, L. Adsorption proprieties and inhibition of mild steel corrosion in $\mathrm{HCl}$ solution by the essential oil from fruit of Moroccan Ammodaucus leucotrichus. Mater. Environ. Sci. 2015, 6, 631-646.

17. El Ouadi, Y.; Lahhit, N.; Bouyanzer, A.; Majidi, L.; Elmsellem, H.; Cherrak, K.; Elyoussfi, A.; Hammouti, B.; Costa, J. Chemical composition and inhibitory effect of essential oil of Lavande (Lavandula dentata) LD on the corrosion of mild steel in hydrochloric acid (1 M). Arab. J. Chem. Environ. Res. 2015, 1, 49-65.

18. Elmsellem, H.; Elyoussfi, H.; Steli, H.; Sebbar, N.K.; Essassi, E.M.; Dahmani, M.; El Ouadi, Y.; Aouniti, A.; El Mahi, B.; Hammouti, B. The theobromine (chocolate) as green inhibitor of mild steel corrosion in hydrochloric acid: Electrochemical and theoretical quantum studies. Der Pharma Chem. 2016, 8, 248-256.

19. El Ouadi,Y.; Lahhit, N.; Bouyanzer, A.; Elmsellem, H.; Majidi, L.; Znini, M.; AbdelRahman, I.; Hammouti, B.; El Mahi, B.; Costa, J. The use of essential oil of Thymus Capitatus originating from north-east Morocco, as eco-friendly corrosion inhibitors of mild steel in hydrochloric acid solution. Int. J. Drug Dev. Res. 2016, 6, 6867-6874.

20. Bendaif, H.; Melhaoui, A.; El Azzouzi, M.; Legssyer, B.; Hamat, T.; Elyoussfi, A.; Aouniti, A.; El Ouadi, Y.; Aziz, M. Eco-friendly Pancratium foetidum Pom extracts as corrosion inhibitors for mild steel in $1 \mathrm{M} \mathrm{HCl}$ media. J. Mater. Environ. Sci. 2016, 7, 1276-1287.

21. Nahlé, A.; El Ouadi, Y.; Bouyanzer, A.; Lhou, M.; Paolini, J.; Desjobert, J.M.; Costa, J.; Chahboun, N.; Zarrouk, A.; Hammouti, B. Evaluation of Melissa officinalis extract and oil as eco-friendly corrosion inhibitor for carbon steel in acidic chloride solutions. Orient. $J$. Chem. 2016, 32, 1909-1921.

22. El Ouadi, Y.; Beladjila, A.; Bouyanzer, A.; Kabouche, Z.; Bendaif, H.; Youssfi, F.; Berrabah, M.; Touzani, R.; Chetouani, A.; Hammouti, B. The palm oil from seed of Phoenix dactylifera (oil of both Deglet Nour and Kentichi) as a natural antioxidants and environment-friendly inhibitors on the corrosion of mild steel in $\mathrm{HCl} 1 \mathrm{M}$. Mor. J. Chem. 2017, 5, 139-152.

23. Avci, G.; Keles, Y. Aqueous extract of Acacia cyanophylla leaves as environmentally friendly inhibitor for mild steel corrosion in $1 \mathrm{M} \mathrm{H}_{2} \mathrm{SO}_{4}$ solution. Surf. Interface Anal. 2011, 43(10), 1311-1317. 
24. Garg, U.; Kumpawat, V.; Chauhan, R.; Tak, R.K. Corrosion inhibition of copper by natural occurring plant Acacia senegal. J. Indian Chem. Soc. 2011, 88, 513-519.

25. Singh, R.; Bhargava, S. Chemical examination and corrosion inhibitive efficiency of Acacia raddiana. Int. J. Green Herb. Chem. 2013, 2, 562-567.

26. Bao, J.; Cai, Y.; Sun, M.; Wang, G.; Corke. H. Anthocyanins, flavonols, and free radical scavenging activity of Chinese bayberry (Myricarubra) extracts and their color properties and stability. J. Agric. Food Chem. 2005, 53, 2327-2332.

27. Arora, S.; Kaushik, D. Free radical scavenging activity of Salvadora persica Linn. Asian J. Chem. 2007, 19, 4638-4644.

28. Bouyanzer, A.; Majidi, L.; Hammouti, B. Effect of eucalyptus oil on the corrosion of steel in $1 \mathrm{M} \mathrm{HCl}$. Bull. Electrochem. 2006, 22, 321-324.

29. Quraishi, A.M.; Singh, A.; Singh, V.K; Yadav, D.K. Green approach to corrosion inhibition of mild steel in hydrochloric acid and sulfuric acid solutions by the extract of Murraya koenigii leaves. Mater. Chem. Phys. 2010, 122, 114-122.

30. Belfilali, I.; Chetouani, A.; Hammouti, B.; Aouniti, A.; Louhibi, S.; Al-Deyab, S.S. Synthesis and application of 1,7-bis(2-hydroxybenzamido)-4-azaheptane as a corrosion inhibitor of mild steel in molar hydrochloric acid medium. Int. J. Electrochem. Sci. 2012, 7, 3997-4013.

31. Kissi, M.; Bouklah, M.; Hammouti, B.; Benkaddour, M. Establishment of equivalent circuits from electrochemical impedance spectroscopy study of corrosion inhibition of steel by pyrazine in sulfuric acidic solution. Appl. Surf. Sci. 2006, 252, 4190-4197.

32. El Ouadi, Y.; Abrigach, F.; Bouyanzer, A.; Touzani, R.; El Assyry, A.; Zarrouk, A.; Hammouti, B. Theoretical and experimental studies on the corrosion inhibition potentials of two tetrakis pyrazole derivatives for mild steel in $1.0 \mathrm{M} \mathrm{HCl}$. Portugaliae Electrochim. Acta 2017, 35, 159-178.

33. Dehri, I.; Ozcan, M. The effect of temperature on the corrosion of mild steel in acidic media in the presence of some sulfur-containing organic compounds. Mater. Chem. Phys. 2006, 98, 316-323.

34. Anand, R.R.; Hurd, R.M.; Hackerman, N. Adsorption of monomeric and polymeric amino corrosion inhibitors on steel. J. Electrochem. Soc. 1965, 112, 138-144.

35. Belfilali, I.; Chetouani, A.; Hammouti, B.; Louhibi, S.; Aouniti, A.; Al-Deyab, S.S. Quantum chemical study of inhibition of the corrosion of mild steel in $1 \mathrm{M}$ hydrochloric acid solution by newly synthesized benzamide derivatives. Res. Chem. Intermed. 2014, 40, 1069-1088

36. Ousslim, A.; Bekkouch, K.; Chetouani, A.; Abbaoui, E.; Hammouti, B.; Aouniti, A.; Elidrissi, A.; Bentiss, F. Adsorption and corrosion inhibitive properties of piperidine derivatives on mild steel in phosphoric acid medium. Res. Chem. Intermed. 2014, 40, 12011221.

37. Wang, M., Li, J., Rangarajan, M.; Shao, Y.; La Voie, E.J.; Huang, T.C.; Ho, C.T. Antioxidative phenolic compounds from Sage (Salvia officinalis). J. Agric. Food Chem. 1998, 46, 4869-4873. 